\title{
An Experience in Recreational Diabetic Day in a Non-governmental Organisation, T1Diams, in Mauritius
}

\author{
Pravesh Kumar Guness ${ }^{1,2}$ \\ ${ }^{1}$ Department of Medecine, University of Reunion, Saint Clothilde, Reunion Island \\ ${ }^{2}$ Department of Medicine/Psychosocial, T1Diams NGO, Quatre Bornes, Mauritius Island
}

\section{Email address:}

praveshkumarguness@gmail.com,admin@t1diams.org

To cite this article:

Pravesh Kumar Guness. An Experience in Recreational Diabetic Day in a Non-governmental Organisation, T1Diams, in Mauritius. American Journal of Health Research. Vol. 5, No. 5, 2017, pp. 141-144. doi: 10.11648/j.ajhr.20170505.14

Received: July 25, 2017; Accepted: August 8, 2017; Published: September 18, 2017

\begin{abstract}
T1Diams, non-profit organisation in the island of Mauritius, has been working on the implementation of therapeutic and educational activities for its members. They regularly organise a recreational diabetic day ('Enjoy life' or 'T1Diams en balade'). Aim: To give an overview of a typical diabetic recreational day. Methods: The author participated in several of these activities organised by the organisation in 2014 and 2015. Results: 22 patients came for that event. 11 ( $\geq 12$ years old) attended the day. The morning session was dedicated to diabetic therapeutic education and was carried out by two diabetes nurses. The afternoon session there were physical activities for those $>12$ years old and low intense activities for the other group. The menu for the lunch was elaborated by a nutritionist. Blood glucose levels were regularly monitored. The patients did their insulin injections. Conclusion: This recreational diabetic day gives an opportunity for parents to be reassured that their diabetic children can be autonomous. The day was carried out in a professional way so as to empower the patients. These activities should be organised regularly during a year.
\end{abstract}

Keywords: T1Diams, Diabetic Recreation Day, Diabetic Therapeutic Education, Type 1 Diabetes

\section{Introduction}

Type 1 diabetes usually affects children and young adults. It is a chronic disease, whereby insulin producing cells (ßeta cells) in the pancreas, are auto destroyed [1], [6]. [9]. Hence, the treatment of this condition is a challenging and lifelong one, and has to be properly managed.

Patients are not properly and fully informed about their disease, and, few have been able to cope with their chronic condition alone. Doctors might be highly qualified at diagnosing and treating diseases, but, they unfortunately fail to allocate sufficient time to educate their patients on their disease [2].

The World Health Organisation (1998) has noted that the quality of treatment is not to the level despite efficient one [2]. Moreover, nonadherence rates for chronic illness regimens and for lifestyle changes is about $50 \%$ since many years [3].

Therapeutic patient education is important for the patients, in order to allow them develop the appropriate skills of self- managing and coping with their chronic condition. Being autonomous, the patients will be able to avoid complications of diabetes, while maintaining a good quality of life. Globally, this will reduce the cost of long-term care of Type 1 diabetes in the society [2], [7].

\section{Methods}

The author was invited to participate in several of these activities organised by the organisation in 2014 and 2015 . He placed himself in the shoes of a Type 1 diabetic patient and took part in all the activities organised for him and the other Type 1 diabetic patients. Clearance was granted by the managing committee of the organisation. In this observational study, the author presented one typical diabetic recreational day. 


\section{Results}

\subsection{The Role of T1Diams in Type 1 Diabetes Therapeutic Education}

T1 Diams is a Mauritian non-profit organisation, which has been founded in 2005, with the aim of caring and selfmanaging Type 1 Diabetes in the island. Its first therapeutic education programme was held in Mauritius, with the collaboration of Children's Hospital (Reunion Island) with only 8 Type 1 diabetic patients. It has now reached 241 patients. For the past 10 years, T1 Diams has been effectively developing and executing diabetic therapeutic education.

They achieve their goals by 4 Types of therapeutic educational interventions:

a) Regular home based diabetes therapeutic education b) Regular diabetic recreation days

c) Annual winter diabetic camp

d) Trimestral news bulletin on Type 1 diabetes and an annual national congress on Type 1 diabetes for health professionals.

\subsection{Diabetic Recreation Day ('T1 Diams en Balade' and 'Enjoy Life')}

The idea of having centres where diabetics can be trained and treated on an outpatient basis is by no means a new concept [5], [8], [10]. T1 Diams regularly organises a monthly recreational diabetic day for its patients- 'Enjoy life' or 'T1Diams en balade'. These two activities is nearly the same as diabetic day care centre in a hospital. In Mauritius it is outside the hospital and is organised by T1Diams.

Table 1. Themes to be covered on a monthly basis.

\begin{tabular}{llll}
\hline Month (Year 2014) & Region & & Theme \\
\hline January & North & T1Diams en Balade & Management of Hyperglycemia \\
February & South & T1Diams en Balade & Management of Hyperglycemia \\
Mars & North & Enjoy Life & Insulin and adaptation \\
April & South & Enjoy Life & Insulin and adaptation \\
May & North & T1Diams en Balade & Nutrition \\
June & South & T1Diams en Balade & Nutrition \\
July & & Annual winter diabetic camp & \\
August & & T1Diams en Balade & Brief general description of the digestive system, What is Type 1 diabetes \\
September & North & T1Diams en Balade & Brief general description of the digestive system, What is Type 1 diabetes \\
October & South & Enjoy Life & Management of Hypoglycemia \\
November & North & Enjoy Life & Management of Hypoglycemia \\
December & South & &
\end{tabular}

'Enjoy Life' is a recreation day, whereby the members are invited for a whole day from $07 \mathrm{hr} 30$ to $16 \mathrm{hr}$, and, where breakfast is included. On the other hand, 'T1 Diams en Balade' starts from to $09 \mathrm{hr}$ to end at $16 \mathrm{hr}$, and, breakfasts are not provided. Since T1 Diams has members all over the island, it has to divide the island in 2 parts- North and South. Each recreation day may thus have a group of either Northern or Southern residents, and each time, a theme is proposed for its therapeutic education.

The idea of organising the activity in the two poles of the island is that people of low socioeconomic status or having a busy schedule and can't attend it has the opportunity to catch up.

The planning of the day is determined well in advance as illustrated in Table 2.

Table 2. Planning of the day.

\begin{tabular}{lll}
\hline & T1Diams en Balade & Enjoy Life \\
\hline $7 \mathrm{~h} 30$ & & Arrival and registration of members \\
$7 \mathrm{~h} 40$ & & glycaemia, insulin injection \\
$7 \mathrm{~h} 40$ & & breakfast \\
$8 \mathrm{~h} 00$ & & presentation of the program \\
$8 \mathrm{~h} 00-$ & & \\
$9 \mathrm{~h} 00$ & & \\
$09 \mathrm{~h} 00-$ & Arrival and registration of members & \\
$09 \mathrm{~h} 10$ & & \\
$09 \mathrm{~h} 00-$ & Glycaemia & \\
$09 \mathrm{~h} 20$ & & \\
$09 \mathrm{~h} 20-$ & Snack & \\
$09 \mathrm{~h} 30$ & & Diabetic therapeutic education \\
$09 \mathrm{~h} 30-$ & presentation of the program & \\
$09 \mathrm{~h} 45$ & & glycaemia, insulin injection \\
$10 \mathrm{~h} 00-$ & Diabetic therapeutic education & \\
$11 \mathrm{~h} 45$ & & lunch \\
$11 \mathrm{~h} 45-$ & glycaemia, insulin injection & \\
$12 \mathrm{~h} 00$ & & free zone \\
$12 \mathrm{~h} 00-$ & lunch & \\
$13 \mathrm{~h} 00$ & & \\
$13 \mathrm{~h} 00-$ & free zone & \\
$13 \mathrm{~h} 30$ & &
\end{tabular}




\begin{tabular}{lll}
\hline & T1Diams en Balade & Enjoy Life \\
\hline $13 \mathrm{~h} 30-$ & physical activities & physical activities \\
$15 \mathrm{~h} 30$ & & \\
$15 \mathrm{~h} 30-$ & glycaemia & glycaemia \\
$16 \mathrm{~h} 00$ & & departure \\
$16 \mathrm{~h} 00$ & departure & . \\
\hline
\end{tabular}

About 40 patients normally attend this day and they are divided in 3 groups, each taken up by the 2 diabetes educator and the general practitioner.

The morning session, $9 \mathrm{hr}$ to $11 \mathrm{hr}$, is allocated to diabetic therapeutic education. Various educational tools are used (written documents, slides, internet, etc.). In the afternoon session, physical activities are organised. Specialised doctors are also invited to do a presentation on a specific subject. These diabetic recreation days give an opportunity for parents to be assured that their diabetic children can be autonomous. The day is carried out in a professional way so as to empower the patients. These activities should be organised regularly during a year, to allow experience sharing.

The author describes one of the recreational diabetic day that he attended in the study.

\subsection{Observations}

For the Enjoy Life that took place in the north of the island, there was 22 Type 1 diabetic patients who attended the event. The activity was organised on the recreation ground of a well-known sugar estate of Mauritius. Prior to the event, the staff of T1Diams sent a letter of invitation to all its 241 members. 2 days before the event the staff calls the members to confirm their presence and their pick up point. Each member has got a pick up point where the transport will pick up the patient and bring them to the recreation site. After having all the confirmed patients, the administration will organising the number of vehicles needed to transport the patients at different places of the island. Each vehicle will have a medical personnel who is present. The latter will have glucose and bread in case of Hypoglycemia. One week before the nutritionist will meet the administrator and the medical to brief on the menu of that day concerning carbohydrate counting. Then the administrator will organise to buy and prepare the menu.

T1Diams called the author to tell him the place and time for the pickup point. He was told that the vehicle will take him at $6 \mathrm{~h} 30$. When he was in the transport he presented himself to the patients and told them to inform him if ever they are not feeling well. After picking up 5 members in my transport we reached the site at $7 \mathrm{~h} 15$. There was a reception desk whereby I register myself and was given a bottle of water for the day. 11 patients $\geq 12$ years and 11 patients less than 12 years. After that I went to the medical room where I check my blood glucose levels as all the patients. I wrote it in a blood glucose logbook. The other patients were doing the same procedure and they did their injection of insulin before their breakfast. Children with a hyperglycemia was allowed to inject insulin before and those having a hypoglycemia was allowed to have their injection just before breakfast (8h). A injection time-glycaemia table was followed as shown in table 3 .

Table 3. Showing injection time and glycaemia.

\begin{tabular}{ll}
\hline Glycaemia (mmol/l) & Time of injection before breakfast/lunch \\
\hline$<3.3$ & Sugar and then injection just before \\
$3.3-8.2$ & 4 mins \\
$8.3-11$ & $10 \mathrm{mins}$ \\
$11.1-16.5$ & $10-15 \mathrm{mins}$ \\
$16.5-22$ & $15-20 \mathrm{mins}$ \\
\hline
\end{tabular}

\subsection{Nutrition}

The nutritionist counselled the patients on the amount and the importance of each food group. There was a variety of items for the breakfast where the patient would choose. For example, 1 egg ( 1 tablespoon sliced mushroom/1/4 tomatoes, herbs), 1 x round whole meal Bread $(100 \mathrm{~g})$, butter, normal Jam- 1 tablespoon, peanut butter, cheese, chocolate cereals, Semi-skim milk-200ml, tea, coffee and sugar. For lunch we got $100 \mathrm{~g}$ whole meal Bread, x3 chicken nuggets, 1x boiled egg, 1 slice fat-reduced cheese and salad (lettuce, cucumber and beetroot).

After breakfast there was a session of 45 minutes where all the invitees presented themselves and was briefed on the programme. That day the theme was' Brief general description of the digestive system, what is Type 1 diabetes'. The group was divided into two (less than 11 years and more than 12 years) and each one a diabetic educator was responsible. For the younger age group the therapeutic session was organised in a simple language to be understood by the children. For the other group 'the path a bread in the body' was used. The site was divided in several paths representing the different path of the body (mouth, oesophagus, stomach, pancreas, insulin, liver, muscle, and intestine and glucose molecules). Everyone followed the path of the 'bread' by walking through different check points representing an organ. The educator was the maestro for that mini trip. Parents and adolescents were allowed to ask questions all along.

\subsection{Specialised Session}

An optometrist attended the recreation day and did a live presentation on diabetes and its complications on the eyes.

\subsection{Physical Activity}

After lunch there was a physical activity organised. The insulin dose was adjusted prior to the activity using a wellestablished protocol. No injection was done in the lower limb as there was a risk of hypoglycaemia during the activity. 
Furthermore any hyperglycemia more that $14 \mathrm{mmol} / 1$ associated with ketones in the urine was not allowed to participate. Instead the ketosis state was treated with a bolus of rapid acting insulin. The aim of organising this session is to empower the members how to manage their Type 1 diabetes with sport.

\subsection{Management of Diabetes Related Emergencies on That Day}

\subsubsection{Hypoglycaemia}

A protocol for hypoglycaemia treatment is available in the medical room. Hypoglycaemia is defined as a blood glucose level $\leq 3.3 \mathrm{mmol} / 1(0.6 \mathrm{~g} / \mathrm{l})$. Five grams of oral glucose per $20 \mathrm{~kg}$ of body weight is given and we wait for 10 mins for symptoms to subside. In case there is persistence of hypoglycaemia, we repeat the oral glucose dose. In case of severe hypoglycaemia, the medical staff is trained on the administration of $30 \%$ glucose intravenous solution or intramuscular injection of glucagon.

Prior to physical activity, the dose of insulin is decreased and a $10 \mathrm{~g}$ glucose equivalent snack is given.

\subsubsection{Hyperglycaemia}

In case of blood glucose readings $\geq 14 \mathrm{mmol} / 1$, the child is requested to do a urine ketone level test. There is a set protocol for the management of hyperglycaemia with or without ketosis. For hyperglycaemia without ketosis, the amount of insulin needed is calculated to correct the elevated blood glucose reading ( 1 unit of rapid acting insulin= 99/ (total dose of insulin over $24 \mathrm{~h}$ )). In the presence of ketosis, the child is given water to prevent dehydration and a calculated amount of insulin is given to reverse ketosis. No physical activity is allowed during that period. The child's condition is followed up using a flow sheet. If the symptoms persist, the child is referred to the nearby regional hospital.

\subsection{Fundings}

The camp's budget is funded by donations from the corporate sector; no funding from government is available. In France, the association Aides Aux Jeunes Diabetiques organises camps ranging from 1 to 3 weeks and these are sponsored by the government and private donors [4].

\section{Conclusion}

Regular recreational diabetic days are important to implement diabetic therapeutic education, as well as to reinforce the experience sharing among the Type 1 Diabetic children. It is one of the rare country in the world having so much endeavour to help the Type 1 patients and their families.

\section{Acknowledgements}

We are grateful to Mr Didier Jean Pierre, Mr Abdullah Dustagheer, Ms Bianca Labonté, Dr Baptiste Valle, and Dr Zahrah Atchia for their help and general support for this article.

The Authors declare that there is no conflict of interest.

\section{References}

[1] American Diabetes Association. 2015. Type 1 Diabetes. [ONLINE] Available at: http://www.diabetes.org/diabetesbasics/Type-1/. [Accessed 26 July 15].

[2] World Health Organization. 1998. Therapeutic Patient Education. [ONLINE] Available at: http://www.euro.who.int/ data/assets/pdf file/0007/145294/ E63674.pdf. [Accessed 26 July 15].

[3] American Diabetes Association Clinical Diabetes. 2006. Improving Patient Adherence.[ONLINE] Available at: http://clinical.diabetesjournals.org/content/24/2/71.full\#sec-2. [Accessed 26 July 15].

[4] L'Aide aux Jeunes Diabétiques. 2014. L'ASSOCIATION L'AIDE AUX JEUNES DIABÉTIQUES ACCOMPAGNE LES FAMILLES. [ONLINE] Available at: http://www.ajddiabete.fr/. [Accessed 02 August 15].

[5] McKendRY, J. B. R.. 1970. A Diabetic Day Care Unit in a General Hospital.[ONLINE] Available at: http://www.ncbi.nlm.nih.gov/pmc/articles/PMC2281762/pdf/c anfamphys00388 -0052.pdf. [Accessed 03 August 15].

[6] Diabetes.co.uk. (2017). Type 1 Diabetes. [online] Available at: http://www.diabetes.co.uk/type1-diabetes.html [Accessed 7 Aug. 2017].

[7] Golay, A., Lagger, G., Chambouleyron, M., Carrard, I. and Lasserre-Moutet, A. (2008). Therapeutic education of diabetic patients. Diabetes/Metabolism Research and Reviews, 24 (3), pp. 192-196.

[8] American Diabetes Association. (2017). Daycare, Camps, and Recreational Programs. [online] Available at: http://www.diabetes.org/living-with-diabetes/know-yourrights/discrimination/public-accommodations/daycare-campsand-recreational-programs/?referrer=https://www.google.mu/ [Accessed 7 Aug. 2017].

[9] Diabetesaustralia.com.au. (2017). Type 1 diabetes. [online] Available at: https://www.diabetesaustralia.com.au/type-1diabetes [Accessed 7 Aug. 2017].

[10] Childrenwithdiabetes.com. (2017). children with DIABETES - Camps for Children with Diabetes. [online] Available at: http://www.childrenwithdiabetes.com/camps/ [Accessed 7 Aug. 2017]. 